\title{
Population genetic analysis of Serpulina pilosicoli and its molecular epidemiology in villages in the Eastern Highlands of Papua New Guinea
}

\author{
Darren J. Trott, ${ }^{1}$ Andrew S. J. Mikosza, ${ }^{1}$ Barry G. Combs, ${ }^{2}$ \\ Sophy L. Oxberry ${ }^{1}$ and David J. Hampson ${ }^{1}$
}

\begin{abstract}
Author for correspondence: David J. Hampson. Tel: +6189360 2287. Fax: +61893104144 e-mail: hampson@numbat.murdoch.edu.au
\end{abstract}

\footnotetext{
1 Division of Veterinary and Biomedical Sciences, Murdoch University, Murdoch, Western Australia 6150, Australia

2 Papua New Guinea Institute of Medical Research, Goroka, Eastern Highlands Province, Papua New Guinea
}

\begin{abstract}
The population genetics of Serpulina pilosicoli and its molecular epidemiology in villages in the Eastern Highlands province of Papua New Guinea were investigated. Multilocus enzyme electrophoresis (MLEE) was used to analyse 164 isolates from humans and animals. These were divided into 33 electrophoretic types (ETs), four of which contained $65 \%$ of the isolates. The mean genetic diversity ( $n=$ number of ETs) for 145 human isolates was $0 \cdot 18$, and the mean number of alleles at five polymorphic loci was 2.6 . The species appeared to be recombinant, as there was a lack of linkage disequilibrium, and $\mathbf{2 5} \%$ of all the possible combinations of alleles was present in the population. PFGE analysis using the enzymes Mlul and Sall divided 157 of the isolates into 99 PFGE types, demonstrating the existence of considerable strain diversity in a geographically restricted area. The two techniques were in excellent agreement; however, PFGE was more discriminatory for strain typing than was MLEE. Nine out of $19(47.4 \%)$ culture-positive individuals were colonized by the same PFGE type of S. pilosicoli when retested after 6 weeks. For three individuals, the PFGE profiles of the second isolate differed from the first in only one or two DNA bands, while the other seven individuals were colonized with distinct PFGE types on each occasion. In two cases, strains with the same PFGE pattern were isolated from humans and dogs, suggesting that crossspecies transmission of $S$. pilosicoli may occur naturally and that the infection can be zoonotic.
\end{abstract}

Keywords: Serpulina pilosicoli, multilocus enzyme electrophoresis (MLEE), pulsedfield gel electrophoresis (PFGE), population genetics, zoonotic transmission

\section{INTRODUCTION}

The spirochaete Serpulina pilosicoli is now recognized as the aetiological agent of intestinal spirochaetosis (Lee \& Hampson, 1994; Trott et al., 1996a; TrivettMoore et al., 1998). In pigs, intestinal spirochaetosis is characterized by the end-on attachment of $S$. pilosicoli to the colonic epithelium, with associated watery to mucoid diarrhoea (Trott et al., 1996b). S. pilosicoli colonizes the large intestine of other animal species, including dogs (Duhamel et al., 1995) and birds (Trott et al., 1996c; McLaren et al., 1997). Although humans

Abbreviations: ET, electrophoretic type; $I_{A}$, index of association; MLEE, multilocus enzyme electrophoresis. can be colonized with the related intestinal spirochaete Brachyspira aalborgi (Hovind-Hougen et al., 1982), this organism is considered to be a non-pathogenic commensal (Hendrik-Nielsen et al., 1983). In contrast, $S$. pilosicoli has been isolated from humans in whom clinical signs, including diarrhoea, together with lesions consistent with intestinal spirochaetosis, have been present (Lee \& Hampson, 1994; Trivett-Moore et al., 1998). In certain immunocompromised or debilitated humans, spirochaetes resembling $S$. pilosicoli have been isolated from regions of the body beyond the large intestine, including the liver (Kostman et al., 1995), and $S$. pilosicoli has been isolated from the bloodstream (Fournié-Amazouz et al., 1995; Trott et al., 1997a). S. pilosicoli most commonly colonizes 
individuals in developing communities (Barrett, 1990; Lee \& Hampson, 1992; Trott et al., 1997b) and male homosexuals and HIV patients in Western societies (McMillan \& Lee, 1981; Cooper et al., 1986; Surawicz et al., 1987; Law et al., 1994; Trivett-Moore et al., 1998), where rates of infection are in the range 30-50\% (Barrett, 1990; Lee \& Hampson, 1992). Infection in other groups is apparently negligible (Tompkins et al., 1981, 1986; Lee \& Hampson, 1992).

Studies based on genetic (Lee et al., 1993a, b; Lee \& Hampson, 1994; Atyeo et al., 1996; Rayment et al., 1997) and phenotypical (Barrett et al., 1996) analyses of $S$. pilosicoli strains have shown these to be diverse. Most of these studies were performed on relatively small numbers of isolates from diverse geographical regions and populations with little opportunity for transmission to occur between them. Despite this, some human, porcine and canine $S$. pilosicoli strains have been shown to be closely related, although not identical (Lee \& Hampson, 1994). Cross-species transmission has been achieved under experimental conditions. Human, porcine and canine strains of $S$. pilosicoli have been used to infect day-old chicks (Dwars et al., 1992; Trott et al., 1995; Muniappa et al., 1996), and a human strain has been shown to cause colitis and crypt abscessation in experimentally infected newly weaned pigs (Trott et al., 1996b).

To date, the population structure of $S$. pilosicoli has not been investigated. Recently, statistical techniques have been applied to multilocus enzyme electrophoresis (MLEE) data to demonstrate that pathogenic bacterial species can occupy a spectrum of population structures (Maynard Smith et al., 1993). Most bacterial species, including those with a high degree of genetic diversity, are clonal, with the majority of allelic variation arising slowly from cumulative genetic mutations. Clonal populations are characterized by the existence of strong linkage disequilibrium and by the repeated recovery of isolates belonging to the same electrophoretic type (ET) from hosts that are temporally and geographically unassociated (Maynard Smith et al., 1993; O'Rourke \& Spratt, 1994). However, several species of pathogenic bacteria, including Neisseria gonorrhoea, Neisseria meningitidis (Maynard Smith et al., 1993), Helicobacter pylori (Go et al., 1996) and the intestinal spirochaete Serpulina hyodysenteriae (Trott et al., 1997c), have population structures that are not in linkage disequilibrium and appear to have been moulded under the influence of extensive genetic recombination.

Previously, we determined the prevalence of $S$. pilosicoli in villagers and their animals in the Asaro valley in the Eastern Highlands province of Papua New Guinea (Trott et al., 1997b). The Highlands region is geographically isolated, and the indigenous people have had significant contact with the outside world only in the last 50 years. The majority of Highlanders live as subsistence farmers in a traditional, closed society, where they have a close association with their animals. The villages lacked modern sanitation facilities and running water, and there was ample opportunity for the widespread dissemination of intestinal spirochaetes via the faecal-oral route. Faecal swabs and epidemiological data were obtained from human beings, pigs, dogs, birds and rats. S. pilosicoli was isolated from 113 out of 496 humans $(22 \cdot 8 \%), 4$ out of $76 \operatorname{dogs}(5 \cdot 3 \%)$ and 1 out of 18 birds $(5.6 \%)$, but it could not be cultured from any village pigs. A high rate of colonization was found in control pigs from a local commercial piggery ( 17 out of 50 pigs; $34 \%$ ). The rate of colonization of humans in the five villages varied from 8.6 to $30.1 \%$, whereas it was $6.5 \%$ in a control group of humans living in an urban environment.

The availability of this collection of $S$. pilosicoli isolates provided a unique opportunity to examine the population structure of the species and its strain diversity and distribution in a remote area. Measurements of linkage disequilibrium from MLEE data are best performed on such populations, where there are no geographical or biological barriers to gene exchange (Maynard Smith et al., 1993).

Therefore, the purpose of the current study was to determine the degree of genetic variation among the $S$. pilosicoli isolates, to investigate factors governing the existence of genetic diversity among the strains and to look for evidence of cross-species transmission between animals and humans. MLEE and PFGE techniques were applied to the collection to help fulfil these aims.

\section{METHODS}

Bacteria. A total of 164 isolates of $S$. pilosicoli were cultured from rectal swabs or faecal specimens. Epidemiological data concerning the isolates have been given previously (Trott $e t$ al., 1997b). Forty-four human isolates and a canine isolate were obtained from village 1,34 human isolates and a canine isolate from village 2 , nine human isolates and an isolate from a duck from village 3, 12 human isolates and two canine isolates from village 4,11 human isolates from village 5 and four isolates from indigenous workers at the Papua New Guinea Institute of Medical Research who lived in the local township of Goroka. Fourteen S. pilosicoli isolates were obtained from European Large White-Landrace cross pigs at a commercial piggery on the outskirts of Goroka. The other human isolates were obtained from village 1 during subsequent resampling 6 and 8 weeks after the first set of isolations. During the second collection, 19 isolates were obtained from individuals who were positive on the first sampling and the remaining 10 were obtained from seven individuals who were negative and three individuals who did not provide a sample on the first occasion. Two isolates were obtained during the third resampling from culture-positive individuals who had been treated 2 weeks previously with $500 \mathrm{mg}$ tinidazole for $3 \mathrm{~d}$.

Culture conditions. Swabs were initially plated onto selective trypticase soy agar medium, as developed for the isolation of Serpulina hyodysenteriae (Jenkinson \& Wingar, 1981), and were incubated in anaerobic jars in an atmosphere of $94 \%$ $\mathrm{N}_{2}$ and $6 \% \mathrm{CO}_{2}$ at $39{ }^{\circ} \mathrm{C}$ for $5-15 \mathrm{~d}$. When intestinal spirochaetes were observed, plates were subcultured up to 10 times to obtain the organisms in pure culture. Bacterial 


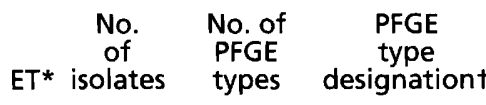

Origin
Genetic distance

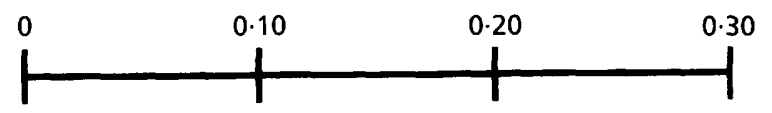

$\begin{array}{ccccc}1 & 1 & 1 & & \text { V2H } \\ 2 & 1 & 1 & & \text { V5H } \\ 3 & 1 & 1 & & \text { V1H } \\ 4 & 1 & 1 & & \text { V1H } \\ 5 & 3 & 1 & & \text { V1H } \\ 6 & 1 & 1 & & \text { V1H } \\ 7 & 2 & 2 & \text { A-B } & \text { V1H } \\ 8 & 2 & 2 & \text { A-B } & \text { V2H } \\ 9 & 1 & 1 & & \text { MMR } \\ 10 & 6 & 5 & \text { A-E } & \text { V1H, V2H, V4H, IMR } \\ 11 & 3 & 3 & \text { A-C } & \text { V1H, V2H } \\ 12 & 2 & 2 & \text { A-B } & \text { V1H, V2H } \\ 13 & 2 & 2 & \text { A-B } & \text { V1H } \\ 14 & 22 & 11 & \text { A-K } & \text { V1H, V2H, V3H,V4H } \\ 15 & 3 & 3 & \text { A-C } & \text { V1H, V2H } \\ 16 & 29 & 13 & \text { A-K; 2 NT } & \text { V1D, V4D, V1H-V5H } \\ 17 & 2 & 2 & \text { A-B } & \text { V2H, V3H } \\ 18 & 1 & 1 & & \text { GP } \\ 19 & 1 & \text { NT } & & \text { V1H } \\ 20 & 1 & 1 & & \text { V1H } \\ 21 & 27 & 5 & \text { A-D; 1 NT } & \text { V1H, V2H, IMR } \\ 22 & 1 & 1 & & \text { V5H } \\ 23 & 1 & 1 & & \text { V4D } \\ 24 & 2 & 1 & \text { A; 1 NT } & \text { V1H } \\ 25 & 2 & 1 & & \text { V1H } \\ 26 & 3 & 3 & \text { A-C } & \text { V5H, GP } \\ 27 & 5 & 4 & \text { A-D } & \text { V2H, V3H, IMR } \\ 28 & 1 & 1 & & \text { GP } \\ 29 & 1 & 1 & & \text { GP } \\ 30 & 3 & 1 & \text { A; 2 NT } & \text { V3Dk, GP } \\ 31 & 2 & 2 & \text { A-B } & \text { GP, V5H } \\ 32 & 28 & 21 & \text { A-U } & \text { V1H-V5H, V2D, GP } \\ 33 & 3 & 3 & \text { A-C } & \text { GP } \\ & & & & \end{array}$

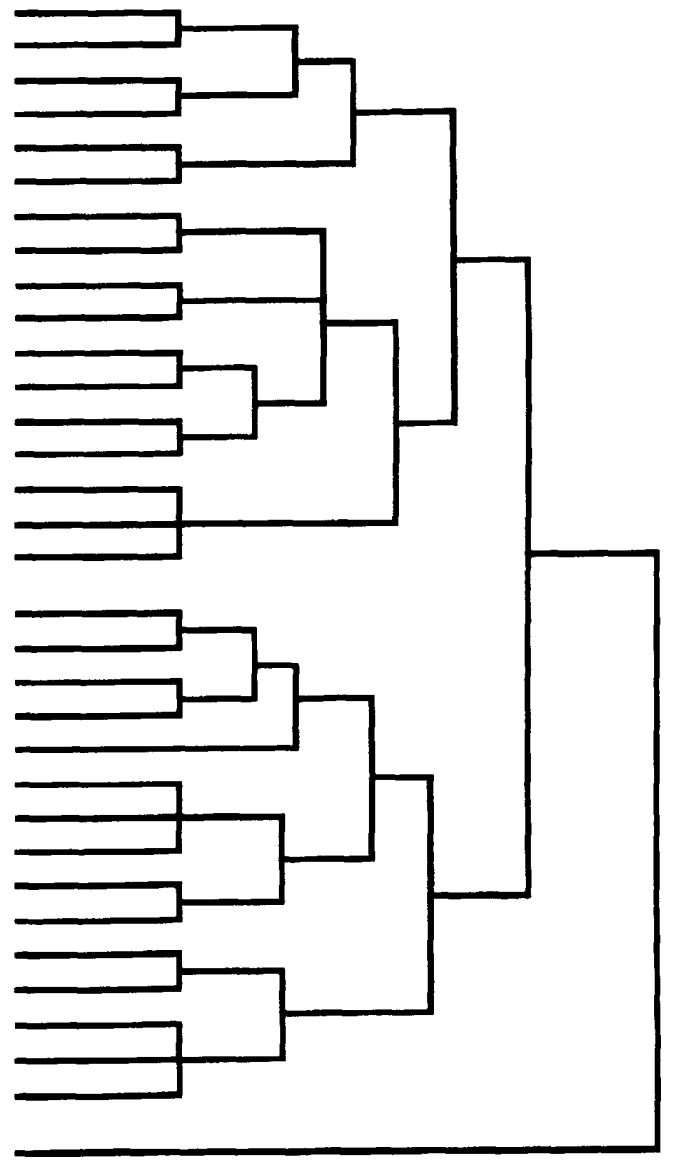

Fig. 1. Phenogram depicting relationships among 164 isolates of S. pilosicoli from humans and animals in the Eastern Highlands of Papua New Guinea, analysed by MLEE and divided into 33 ETs and three divisions. The number of isolates in each ET, the number of PFGE types, their designation and origin are also shown. The unweighted pair group method with arithmetic averages was used to construct the phenogram. *Electrophoretic types: 1-17, division 1; 18-32, division 2; 33, division 3. †PFGE designations according to ET number followed by upper-case alphabetical letter; NT, not tested by PFGE. $¥ V 1-V 5$, villages $1-5 ; \mathrm{H}$, isolate from a human; $\mathrm{D}$, isolate from a dog; GP, isolate from a pig; Dk, isolate from a duck; IMR, isolate from workers at the Institute of Medical Research.

colonies from pure plates were subcultured at least three times before inoculation into $7 \mathrm{ml}$ Kunkle's anaerobic broth medium (Kunkle et al., 1986) and incubated at $37^{\circ} \mathrm{C}$ on a rocking platform for 72-96 hor until mid-exponential-phase growth was achieved. Cultures deemed pure by phasecontrast microscopy were transferred into $500 \mathrm{ml}$ Kunkle's medium and again incubated at $37^{\circ} \mathrm{C}$ on a rocking platform for 72-96 h. Aliquots from mid-exponential-phase cultures $\left(10^{8}-10^{9}\right.$ cells $\left.\mathrm{ml}^{-1}\right)$ were preserved at $-80^{\circ} \mathrm{C}$, and the remainder was centrifuged $\left(10000 \mathrm{~g}\right.$ at $4^{\circ} \mathrm{C}$ for $\left.20 \mathrm{~min}\right)$, washed in sterile PBS $(0.145 \mathrm{M} \mathrm{NaCl}, 0.15 \mathrm{M}$ sodium phosphate; $\mathrm{pH} 7 \cdot 2)$ and centrifuged again $\left(10000 \mathrm{~g}\right.$ at $4{ }^{\circ} \mathrm{C}$ for $20 \mathrm{~min}$ ). The resulting pellet was divided evenly into two portions. One portion was suspended in approximately $300 \mu \mathrm{l}$ sterile distilled water and was used for the preparation of cell lysate for MLEE analysis. The remaining portion for
PFGE analysis was suspended in cell suspension buffer $(0.05 \mathrm{M}$ Tris, $0.05 \mathrm{M}$ EDTA, $20 \%$ sucrose, $\mathrm{pH} 8.0)$ and held at $-20^{\circ} \mathrm{C}$ at a concentration of approximately $10^{10}$ cells $\mathrm{ml}^{-1}$.

Confirmation of identity by PCR. The identity of the $164 \mathrm{~S}$. pilosicoli isolates in the collection was confirmed by a PCR test based on amplification of part of the 16S rRNA gene. The protocol used, including primers and reaction conditions, was for a hot-start two-phase reaction previously determined and optimized in our laboratory for the identification of S. pilosicoli (Park et al., 1995; Atyeo et al., 1996). A wooden toothpick was dipped into the bacterial pellet obtained after centrifugation of the culture and lightly touched onto the top layer of the PCR reaction. For each isolate, three areas of the pellet were sampled individually and placed into separate PCR reactions. Each batch of PCR 
amplifications included DNA from positive ( $S$. pilosicoli strain $\left.\mathrm{P} 43 / 6 / 78^{\mathrm{T}}\right)$ and negative $(S$. hyodysenteriae strain $\left.\mathrm{B} 78^{\mathrm{T}}\right)$ control cultures.

MLEE and statistical analysis. The methods used for cell preparation, buffers, enzyme systems and running conditions for MLEE analysis were as described previously for intestinal spirochaetes (Lymbery et al., 1990; Lee et al., 1993a). The allelic profiles of 15 constitutive enzyme loci were examined: acid phosphatase (ACP), alcohol dehydrogenase $(\mathrm{ADH})$, hexokinase $(\mathrm{HK})$ and nucleoside phosphorylase (NP) were assayed using a Tris-maleate (pH 7.4) buffer system; alkaline phosphatase (ALP), phosphoglucose isomerase (PGI), guanine deaminase (GDA) and mannose phosphate isomerase (MPI) using a phosphate $(\mathrm{pH} 7)$ buffer system; esterase (EST), fructose 1,6-diphosphatase (FDP), L-leucyl-glycyl-glycine peptidase, phosphoglucomutase (PGM) and superoxide dismutase (SOD) using a discontinuous buffer system (Tris-citrate gel buffer, $\mathrm{LiOH}$ electrode buffer); and arginine phosphokinase (AK) and glutamate dehydrogenase (GDH) using a discontinuous buffer system (Tris-citrate gel buffer, borate electrode buffer). Mobility variants of an enzyme were interpreted as the products of different alleles at the locus encoding the enzyme and were numbered in order of decreasing rate of anodal migration. Isolates with identical enzymic profiles at all loci were grouped into an electrophoretic type (ET). ETs obtained for the Papua New Guinean isolates were compared directly with those obtained in previous MLEE studies of $S$. pilosicoli in our laboratory, using the same numbering system for allele designation (Lee et al., 1993a, b; Lee \& Hampson, 1994).

Statistical analysis of the MLEE results was only conducted on the human isolates. Genetic diversity $(h)$, a measure of the amount of allelic variation at each enzyme locus, was calculated as $h=\left(1-\Sigma p_{i}^{2}\right)(n / n-1)$, where $p_{i}$ is the frequency of the indicated allele and $n$ is the number of ETs or isolates (Nei, 1977). Haplotypic diversity $(H)$, a measure of the frequency of haplotypes within the population, was calculated as $H=1-\Sigma p_{j}^{2}$, where $p_{j}$ is the frequency of the $j$ th genotype (Fuste et al., 1996). A phenogram was generated to illustrate the genetic relationships between ETs using the unweighted pair group method with arithmetic averages clustering fusion strategy (Burr, 1968, 1970). Genetic distance between ETs was calculated by pairwise comparison as the proportions of loci at which dissimilar alleles occurred. Linkage disequilibrium was calculated according to the measurement devised by Maynard Smith et al. (1993). Linkage disequilibrium is calculated on the basis of the distribution of allelic mismatches between pairs of isolates, ETs or clonal groups among all loci. The ratio of variance observed in mismatches $\left(V_{0}\right)$ to variance expected at linkage disequilibrium $\left(V_{\mathrm{e}}\right)$ is expressed as the index of association $\left(I_{\mathrm{A}}\right)$, where $I_{\mathrm{A}}=V_{\mathrm{o}} / V_{\mathrm{e}}-1$. In clonal populations, $I_{\mathrm{A}}$ is significantly different from zero, whereas in populations in which large-scale random recombination is occurring the value is very close to zero or may be negative.

PFGE. The methods used for the preparation of DNA from cells, DNA restriction digests and PFGE were as described previously (Atyeo et al., 1996), except that the gel was subjected to electrophoresis at $180 \mathrm{~V}$ for $18 \mathrm{~h}$ with a pulse time ramped from 1 to $50 \mathrm{~s}$. DNA from all isolates was restricted with $M l u \mathrm{I}$, and $S a l \mathrm{I}$ was then used to attempt to differentiate strains found to have the same pattern with MluI. PFGE types were designated by their ET number and a capital letter (e.g. in ET 32, there were 21 PFGE types, designated $32 \mathrm{~A}-32 \mathrm{U})$.

\section{RESULTS}

MLEE: genetic relationships between isolates

The $164 \mathrm{~S}$. pilosicoli isolates were divided into 33 electrophoretic types (ETs) (Fig. 1, Table 1). These ETs were divided into two major divisions separated by a genetic distance of 0.22 and a third minor division separated from the other groups at a genetic distance of 0.29 (Fig. 1). Division I (ETs 1-17) consisted mainly of human isolates, with isolates from two village dogs in ET 16. Division II (ETs 19-32) included isolates from humans, pigs, dogs and a duck. Four ETs within division II contained $S$. pilosicoli isolates from more than one species. ETs 26 and 31 contained isolates from humans and pigs, ET 30 from pigs and a duck and ET 32 from humans, pigs and a dog. Division III (ET 33) contained three porcine isolates. The majority of isolates $(65 \%$ of all isolates and $69 \%$ of the human isolates) were located in ET 14 (22 isolates), ET 16 (29 isolates including two from dogs), ET 21 ( 27 isolates) and ET 32 (28 isolates including one from a dog and three from pigs). Two of these ETs (16 and 32) also contained isolates from all five villages. ET 14 contained isolates from villages $1-4$, and ET 21 contained $21(28 \%)$ of the isolates obtained from village 1 . The ratio of isolates to ETs in each village ranged from 1.87 in village 3 to 4.17 in village 1 . However, village 1 contained some isolates taken from the same individuals at different times. Of the 19 repeat samples, 13

Table 1. Number of isolates, ETs, mean genetic diversity ( $n=$ number of ETs), ratio of isolates to ETs and number of PFGE types, according to place of origin

\begin{tabular}{|c|c|c|c|c|c|}
\hline Origin & $\begin{array}{c}\text { No. } \\
\text { isolates }\end{array}$ & $\begin{array}{l}\text { No. } \\
\text { ETs }\end{array}$ & $\begin{array}{c}\text { Isolates/ } \\
\text { ETs }\end{array}$ & $\begin{array}{l}\text { Mean } \\
\text { genetic } \\
\text { diversity }\end{array}$ & $\begin{array}{c}\text { PFGE } \\
\text { types }\end{array}$ \\
\hline \multicolumn{6}{|l|}{ Village } \\
\hline 1 & 75 & 18 & $4 \cdot 17$ & 0.18 & 40 \\
\hline 2 & 34 & 12 & $2 \cdot 83$ & $0 \cdot 14$ & 24 \\
\hline 3 & 9 & 5 & 1.8 & $0 \cdot 11$ & 8 \\
\hline 4 & 12 & 4 & 3 & NT & 8 \\
\hline 5 & 11 & 6 & $1 \cdot 87$ & 0.16 & 7 \\
\hline IMR* & 4 & 4 & 1 & NT & 4 \\
\hline Total & 145 & $27 \dagger$ & $5 \cdot 37$ & $0 \cdot 18$ & $88 \ddagger$ \\
\hline Piggery & 14 & 8 & 1.75 & NT & 9 \\
\hline Village dogs & 4 & 8 & $1 \cdot 33$ & NT & 4 \\
\hline Duck & 1 & 1 & NT & NT & NT \\
\hline Total & 164 & 33 & 4.97 & NT & 99 \\
\hline
\end{tabular}

NT, Not tested.

*IMR, isolates obtained from workers at the Papua New Guinea Institute of Medical Research living in Goroka.

$\dagger$ Ten ETs contained isolates from more than one geographical location (Fig. 1).

$\ddagger$ Six PFGE types (16A in villages 1,3 and $4 ; 16 \mathrm{~J}$ and $21 \mathrm{~A}$ in villages 1 and $2 ; 32 \mathrm{~A}$ and $32 \mathrm{~K}$ in villages 2 and 4 ; and $32 \mathrm{M}$ in villages 2 and 3 ) contained isolates from more than one geographical location. 
Table 2. Allele frequencies and genetic diversity using the number of electrophoretic types $(h)$ among 145 S. pilosicoli isolates obtained from humans in Papua New Guinea, examined at 15 enzyme loci and divided into $27 \mathrm{ETs}$

\begin{tabular}{|c|c|c|c|c|c|c|c|c|}
\hline \multirow[t]{2}{*}{ Enzyme* } & \multicolumn{8}{|c|}{ Frequency of indicated allele } \\
\hline & $\mathbf{0}$ & 1 & 2 & 3 & 4 & 5 & 6 & $\boldsymbol{h}$ \\
\hline LGG & 0.00 & $0 \cdot 48$ & $0 \cdot 37$ & $0 \cdot 15$ & $0 \cdot 00$ & 0.00 & 0.00 & 0.63 \\
\hline $\mathrm{AK}$ & $0 \cdot 00$ & $0 \cdot 00$ & $0 \cdot 33$ & $0 \cdot 00$ & $0 \cdot 56$ & 0.00 & $0 \cdot 11$ & 0.59 \\
\hline GDH & 0.00 & 0.48 & $0 \cdot 52$ & $0 \cdot 00$ & 0.00 & 0.00 & 0.00 & $0 \cdot 52$ \\
\hline GDA & 0.00 & $0 \cdot 00$ & $0 \cdot 00$ & 0.00 & $0 \cdot 11$ & $0 \cdot 22$ & 0.67 & 0.51 \\
\hline EST & $0 \cdot 00$ & $0 \cdot 00$ & $0 \cdot 00$ & $0 \cdot 26$ & 0.74 & $0 \cdot 00$ & $0 \cdot 00$ & $0 \cdot 40$ \\
\hline NP & 0.00 & $0 \cdot 00$ & $0 \cdot 00$ & $0 \cdot 00$ & $1 \cdot 00$ & 0.00 & 0.00 & 0.00 \\
\hline PGM & 0.00 & 0.00 & 1.00 & 0.00 & 0.00 & 0.00 & 0.00 & 0.00 \\
\hline $\mathrm{ADH}$ & 0.00 & 0.00 & 0.00 & $1 \cdot 00$ & 0.00 & $0 \cdot 00$ & 0.00 & 0.00 \\
\hline HEX & 0.00 & 1.00 & 0.00 & 0.00 & $0 \cdot 00$ & 0.00 & 0.00 & 0.00 \\
\hline PGI & 0.00 & 0.00 & 0.00 & 0.00 & 1.00 & 0.00 & 0.00 & 0.00 \\
\hline MPI & 0.00 & 0.00 & 1.00 & 0.00 & $0 \cdot 00$ & 0.00 & 0.00 & 0.00 \\
\hline SOD & 0.00 & 0.00 & 1.00 & 0.00 & 0.00 & 0.00 & 0.00 & 0.00 \\
\hline ALP & 0.00 & 0.00 & 1.00 & 0.00 & 0.00 & 0.00 & 0.00 & 0.00 \\
\hline FDP & 0.00 & 0.00 & $0 \cdot 00$ & 0.00 & 1.00 & 0.00 & 0.00 & 0.00 \\
\hline $\mathrm{ACP}$ & 0.00 & 0.00 & 0.00 & 0.00 & 0.00 & 0.00 & $1 \cdot 00$ & 0.00 \\
\hline \multicolumn{8}{|c|}{ Mean genetic diversity } & $0 \cdot 18$ \\
\hline
\end{tabular}

* See Methods for enzyme abbreviations.

$(68.4 \%)$ had identical allele profiles to the corresponding isolate obtained on the first sampling, while six were located in unrelated ETs. No new ETs were generated by the addition of new isolates from the repeat samplings. Two people (V1H56 and V1H82) out of the 19 provided a positive third sample 2 weeks after the second sample, after receiving treatment with tinidazole. The three isolates from villager $\mathrm{H} 56$ were all different, being in ETs 26,32 and 16, respectively. For villager H82, the first and third samples were both in ET 16, while the second sample was in ET 14.

\section{Population genetic analysis of the human isolates}

The 145 isolates from humans were located in 27 ETs. The mean number of alleles per locus was $1 \cdot 53$. Only five loci were polymorphic with two or three alleles, and the other 10 loci were monomorphic (Table 2). The mean genetic diversity per locus was $0 \cdot 18$ based on the number of ETs and 0.12 based on the number of isolates (Table 3). Mean genetic diversities $(n=$ number of ETs) for each of the villages ranged from 0.11 to 0.18 . The total number of possible allelic combinations given the high degree of monomorphic alleles was 108 , and a high proportion of these $(25 \%)$ was observed in the population. The mean genetic distance per locus was $0 \cdot 1$, indicating that the majority of ETs were only separated by 1-2 allele differences. The index of association was calculated as $0 \cdot 20 \pm 0 \cdot 04$ using the number of human isolates, and $-0.09 \pm 0.09$ using the number of ETs. Both these figures were not significantly different from zero.

\section{PFGE}

Using the enzymes $M l u \mathrm{I}$ and $S a l \mathrm{I}, \mathrm{PFGE}$ divided 157 isolates into 99 subtypes (Fig. 1). Of the four ETs with the most isolates (ETs 14, 16, 21 and 32), three

Table 3. MLEE data for human S. pilosicoli isolates obtained from Papua New Guinea, Australian Aborigines and a reference collection

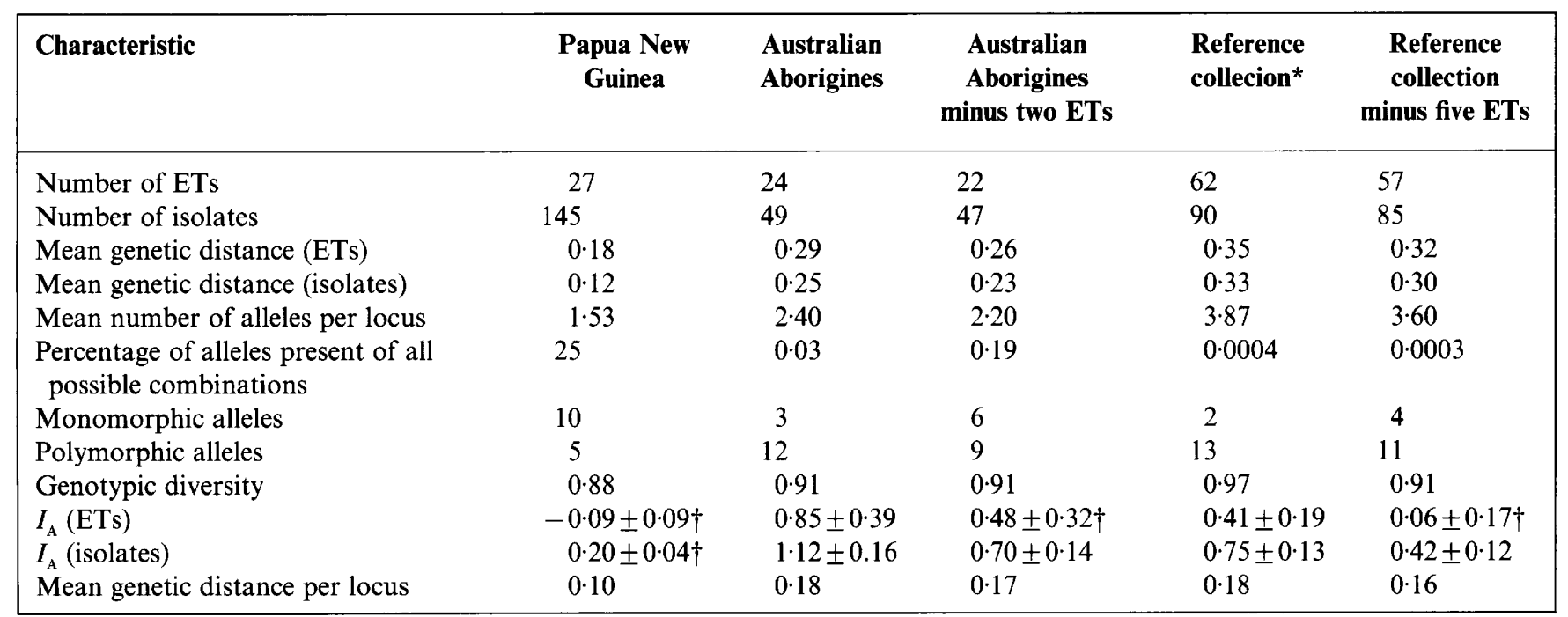

* The reference collection includes all the isolates from Australian Aborigines, as well as isolates from New South Wales, Oman, Italy, UK and USA. The isolates from Papua New Guinea were not included.

$\dagger I_{\mathrm{A}}$ values not significantly different from zero. 


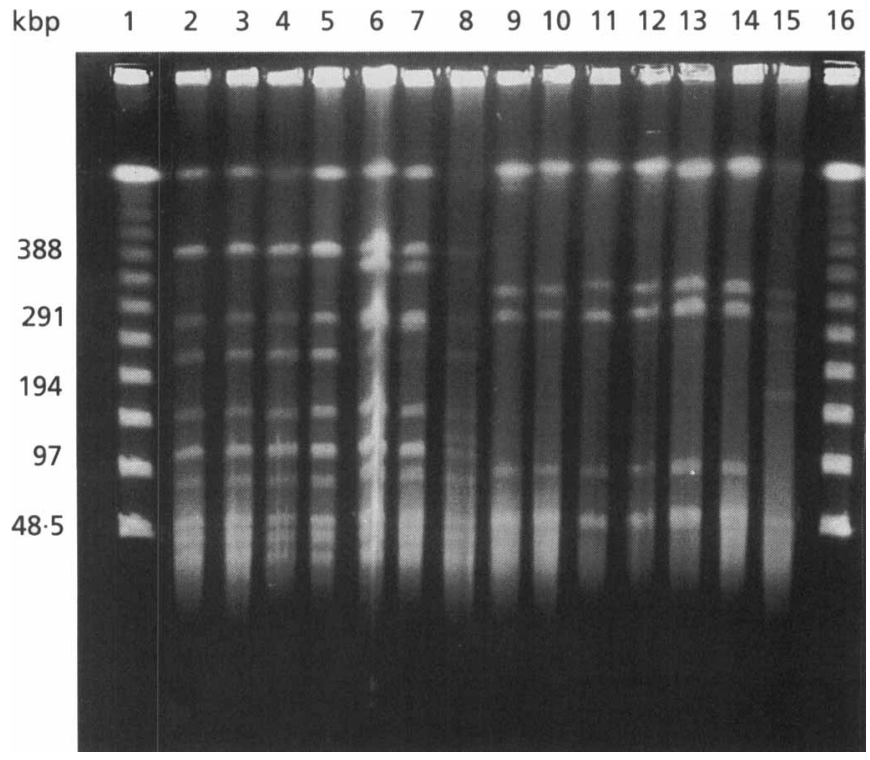

\begin{abstract}
Fig. 2. Agarose gel showing PFGE patterns of seven $S$. pilosicoli isolates belonging to ET 16, digested with Mlul (lanes 2-8) or Sall (lanes 9-15). Lambda molecular mass markers are in lanes 1 and 16 . The order of isolates in lanes 2-8 and 9-15 are V1D1, V1H128, V1H78, V4H6, V1H95, V3H12 and V1H57. Lanes $2-5$ show PFGE type 16A, shared here by one canine and three human isolates, and lanes 6-7 show PFGE type 16B, shared by two human isolates. Pattern 16B differs from pattern $16 \mathrm{~A}$ by the presence of an extra DNA band of approximately $350 \mathrm{kbp}$. Digestion of the same isolates with Sall (lanes 9-15) confirms these differences.
\end{abstract}

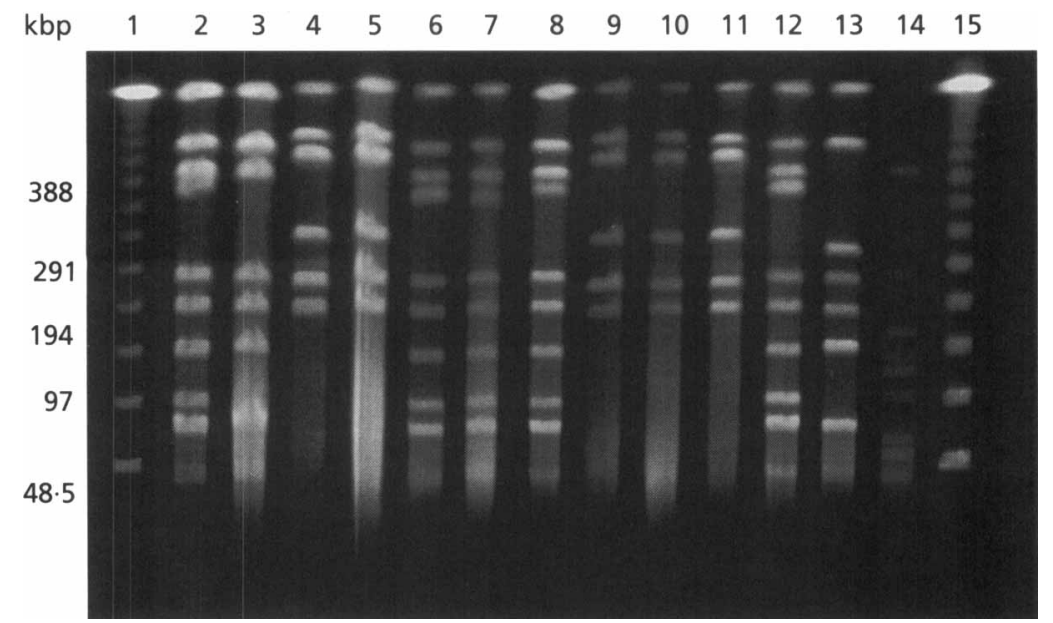

Fig. 3. Agarose gel showing PFGE patterns of eight $S$. pilosicoli isolates belonging to ET 21, digested with Mlul (lanes 2, 3, 6-8 and 12-14) or Sall (lanes 4, 5 and 9-11). These isolates were derived from four villagers, three of whom were sampled on two or three occasions: isolates designated $\times 2$ were recovered from the same individual 6 weeks after the first sampling, and that designated $\times 3$ was isolated 2 weeks after the second sampling, after the individual was treated with tinidazole. Lambda DNA molecular mass markers are in lanes 1 and 15. Isolates in lanes 2 and $3(\mathrm{M} / \mathrm{Ul})$ and 4 and 5 (Sall) are $\mathrm{V} 1 \mathrm{H} 146$ and $\mathrm{V} 1 \mathrm{H} 146 \times 2$; in lanes 6-8 (M/Ul) and 9-11 (Sa/l), they are V1H91, $\mathrm{V} 1 \mathrm{H} 91 \times 2$ and $\mathrm{V} 2 \mathrm{H} 106$; in lanes 12-14 (Mlul), they are $\mathrm{V} 1 \mathrm{H} 56, \mathrm{~V} 1 \mathrm{H} 56 \times 2$ and $\mathrm{V} 1 \mathrm{H} 56 \times 3$. Digestion with Sall confirmed the designations obtained with Mlul. Isolates in lanes 2, 4 and 6-12 have PFGE type 21A; those in lanes 3 and 5 have type 21B; and those in lanes 13 and 14 have types 321 and $16 \mathrm{D}$, respectively. Pattern 21B differs from $21 \mathrm{~A}$ in that it lacks a DNA band at approximately $100 \mathrm{kbp}$.

contained a relatively large range of distinct strains (ratio of isolates to PFGE genotypes 2:3:1), while the 27 isolates in ET 21 had only five PFGE genotypes (ratio of isolates to PFGE genotypes $>5: 1$ ). The most diverse of the ETs (ET 32), which contained 28 isolates, had a ratio of $1 \cdot 3: 1$. The large number of PFGE types overall confirmed the presence of considerable strain diversity among the collection. Only six PFGE types included isolates from more than location, and these all belonged to three of the four ETs with large numbers of isolates (ETs 16, 21 and 32). PFGE pattern $16 \mathrm{~A}$ was present in three villages (villages 1,3 and 4), PFGE patterns 16J, 21 A, 32A, K and M were present in combinations of two villages, and the remaining
PFGE types were only present at a single geographical location (Fig. 1). The majority of PFGE types were only represented by one to three isolates. The exceptions were PFGE types 14A (six isolates, all from village 4), 14D (five isolates, all from village 2), 16A (eight isolates from villages 1,3 and 4), 16G (five isolates from village 5), 21A (13 isolates from villages 1 and 2 ) and 21 B (10 isolates from village 1).

An isolate from a dog in village 1 (V1D1) in ET 16 had the same PFGE banding pattern (16A) as isolates from seven villagers from three different villages $(\mathrm{V} 1 \mathrm{H} 78$, V1H95, V1H114, V1H128, V3H12 and V4H6) (Fig. 2). Another dog isolate (V2D2) in ET 32 had the same 
banding pattern (32A) as a human isolate from another village. The two remaining canine $S$. pilosicoli isolates were obtained from puppies from the same litter. Each belonged to a different ET and had a unique PFGE banding pattern.

The porcine $S$. pilosicoli isolates showed considerable strain diversity. Isolates in MLEE division II were divided into six PFGE types, and the three strains in ET 33 of division III were all different.

Thirteen of the 19 isolate pairs from repeat samplings of the same individuals in village 1 belonged to the same ET, and nine pairs $(47.3 \%)$ had identical PFGE patterns. Three of the non-identical pairs were closely related and were distinguished only by one or two band differences (Fig. 3).

\section{DISCUSSION}

Considerable strain diversity was found among the $S$. pilosicoli collection, with the 145 human isolates divided into 27 ETs and 88 PFGE types. The $I_{\mathrm{A}}$ values from the MLEE data for these isolates were consistent with the panmictic model of population structure (Maynard Smith et al., 1993), in which the disruption to linkage disequilibrium is thought to be caused by the occurrence of extensive genetic recombination. Among the human isolates, however, only five of the 15 loci examined were polymorphic, with a mean of $2 \cdot 6$ alleles at these loci. In other apparently highly recombinant bacterial species investigated by MLEE, the majority of loci have been polymorphic (O'Rourke \& Stevens, 1993; Go et al., 1996; Trott et al., 1997c) and, in the case of $H$. pylori, there was a mean of 11.2 alleles per locus (Go et al., 1996). For this collection of $S$. pilosicoli isolates, the presence of a majority of monomorphic loci suggests that, if extensive large-scale genetic recombination was occurring, it was for some reason restricted to a minority of loci, or it did not result in detectable alterations in electrophoretic mobility for the other enzymes. Nevertheless, consistent with a recombinant population, a high proportion $(25 \%)$ of the possible combinations of the five polymorphic alleles that could be generated was present in the population, and these alleles were not clonally distributed in the phenogram. For example, isolates located in ET 16 of division I of the phenogram were separated from isolates in ET 15 by a single allele difference in the enzyme LGG (genetic distance 0.67 ) but were also separated from isolates in ET 22 in division II by a single allele difference in the enzyme AK (genetic distance 0.22 ).

Unexpectedly, 100 of the 145 human isolates $(69 \%)$ and six of 19 animal isolates were located in only four of the 33 ETs $(12 \%)$. In non-clonal recombinant populations, isolates with the same allele profile (i.e. belonging to the same ET) may be generated by random association of the most common alleles at each locus. In the case of Neisseria gonorrhoea, which has a recombinant population structure, $15 \%$ of 227 isolates were shown to be located in a single ET, based on the examination of nine enzyme loci (O'Rourke \& Stevens, 1993). Subsequent genetic and phenotypical analysis of 26 isolates belonging to this ET showed that they could be divided into 24 distinguishable groups and so were not members of a clone (O'Rourke \& Spratt, 1994). Similarly, in the present study, groups of isolates in each of the four numerically dominant ETs could be divided into 5-21 PFGE types, challenging the notion that they represented stable clones of organisms.

The fact that genetic variation was only detected at five loci helps to explain the clustering of the majority of isolates into four ETs. The MLEE profile of ET 32 represented a combination of the most common alleles in the population, and the remaining three ETs represented combinations of four of the five most common alleles. Another possible interpretation is that the four ETs may represent recently emerged groups with selective survival or virulence advantages, which have since undergone further recombination or mutation (as evidenced by their division into distinct PFGE types). Such recombinant bacterial populations are said to have an epidemic population structure and are normally characterized by an $I_{\mathrm{A}}$ value for the number of isolates that is significantly different from zero (Maynard Smith et al., 1993; Trott et al., 1997c). In the present study, the $I_{\mathrm{A}}$ value for the number of isolates was not significantly different from zero but, as this only involved the analysis of five polymorphic loci, it may be an underestimation of any clonality in the population.

To investigate these conflicting findings further, comparison was made between these results and those from a smaller prevalence study conducted among aboriginal children in the remote north-west of Western Australia (Lee \& Hampson, 1992). MLEE data sets from both studies are shown in Table 3, together with MLEE data from all of the human strains in our reference collection, except for those isolated from Papua New Guinea. The collection is diverse and represents strains from Australia (including those from the study among Australian Aborigines), UK, Oman, Italy and the USA (Lee \& Hampson, 1994). The small $S$. pilosicoli collection recovered from the remote aboriginal community was much more genetically diverse than the Papua New Guinean collection, with 12 polymorphic alleles and a higher mean genetic diversity $(0-29)$. It is not clear why there should be differences in diversity between the two locations and why additional loci would be polymorphic in Australian isolates. One explanation could be that, if the recombination that was deduced to occur in the Papua New Guinean collection was caused by sitespecific recombination, for example associated with specialized transducing bacteriophages, it is possible that the Papua New Guinean isolates were exposed to a smaller or different range of such agents. A generalized transducing bacteriophage has been identified in the related intestinal spirochaete Serpulina hyodysenteriae (Humphrey et al., 1995, 1997), and 
MLEE data for this species indicate that it also undergoes extensive genetic recombination (Trott et al., 1997c). Preliminary studies suggest that a similar phage may exist for $S$. pilosicoli (T. B. Stanton, personal communication), but no other extrachromosomal elements have been reported in the species.

Another apparent discrepancy was found between the data for the Papua New Guinean and Australian aboriginal collections. The $I_{\mathrm{A}}$ values for the aboriginal collection for both the number of isolates and the number of ETs were significantly different from zero, therefore indicating clonality. It is difficult to reconcile a situation in which a bacterial population is apparently clonal in one group of individuals and recombinant in another. A possible reason for the difference between the two populations can be found by examining the $I_{\mathrm{A}}$ value for the entire (non-Papua New Guinean) $S$. pilosicoli reference collection of 90 isolates, which was divided into $62 \mathrm{ETs}$. The $I_{\mathrm{A}}$ values of 0.75 for the number of isolates and 0.41 for the number of ETs also suggest clonality. However, five of the 62 ETs had extremely diverse allele profiles and appeared to be unrelated to each other as well as to the remaining $S$. pilosicoli ETs. While these strains have the phenotypical characteristics of the species (Trott $e t$ al., 1996c, d) and are positive in a 16S rRNA gene amplification PCR reaction that is specific for $S$. pilosicoli (Park et al., 1995), it may be that they are too genetically distant from other $S$. pilosicoli strains to allow homologous recombination. When their allele profiles were removed from the analysis, the $I_{\mathrm{A}}$ value ( $n=$ number of ETs) was no longer significantly different from zero, suggesting that recombination occurred among the remainder of the $S$. pilosicoli strains. Two of these atypically diverse strains were from the aboriginal community and, when their profiles were removed from the analysis, the $I_{\mathrm{A}}$ value ( $n=$ number of ETs) for the aboriginal $S$. pilosicoli population was no longer significantly different from zero. The $I_{\mathrm{A}}$ for the number of isolates among the aboriginal $S$. pilosicoli collection was still significantly different from zero, indicating the presence of certain over-represented clones, i.e. an epidemic population structure. The fact that two of the ETs, which were separated by a single allele difference, contained $32.7 \%$ of the isolates or that the collection was relatively small and may not have been representative of the total number of MLEE types present in the community may help to explain this result. Interestingly, only ETs 3 and 12 were present in both the Papua New Guinean and aboriginal populations. These ETs also contained single isolates from homosexual males in Sydney, New South Wales, and were the only ETs in the collection to contain multiple isolates from different geographical locations.

In this study, the isolation of $S$. pilosicoli on agar favoured the selection of single bacterial clones from individual clinical samples. The high overall prevalence of infection $(22.8 \%)$, the large number of strains identified and their considerable haplotypic diversity $(0 \cdot 89)$, however, all make it likely that individuals may be colonized by more than a single strain. Different strains were isolated from six of the 19 culture-positive individuals who were colonized 6 weeks after they had provided an initial sample. Additionally, isolates obtained from two individuals who received tinidazole were genetically distinct from the isolates obtained from the same individuals before antibiotic treatment. Either reinfection with a new strain had occurred or the individual was originally colonized by more than one strain. Future studies should attempt to obtain several isolates from an individual at the same time and over successive time periods and to demonstrate whether they are the same or different.

Nine of the 19 repeat sample pairs were shown to have the same PFGE type at both samplings, indicating persistent infection or reinfection with the same strain. In three of the 19 paired samples, the strains belonged to the same ET but differed in their PFGE $M l u \mathrm{I}$ patterns by one to two bands. These strains were identical by PFGE using SalI, suggesting that the band differences may have been caused by a single genetic event. While reinfection or co-infection with a closely related strain cannot be ruled out, recombination or mutation may have occurred during the 6 week period that the individual was colonized.

In two cases, isolates with the same PFGE type were recovered from both dogs and humans, suggesting that cross-species transmission may have occurred. The PFGE profile (16/A) from one of the isolates from a dog in ET 16 was identical to seven other human isolates in the same ET. PFGE type 16/A contained isolates from three separate villages, so it appears to be a strain that is widely disseminated and, hence, likely to be readily transmitted. The isolate from a dog with PFGE type 32/A was the same as a single human isolate (V4 H48). In this case, there was no evidence for direct contact, as the dog was from village 2 and the human was from village 4 . As the initial study found a much higher prevalence of $S$. pilosicoli in humans than in dogs and PFGE type 16/A included isolates from seven humans in different villages, it is more likely that transmission was from humans to dogs, for example by dogs eating human faeces. These results support the findings of Koopman et al. (1993), who showed that RFLP patterns of intestinal spirochaetes isolated from humans and dogs in Europe were highly similar and occasionally identical.

The majority of the PFGE types were represented by only one to three isolates, and these were all recovered from the same location. The most commonly represented ETs were divided into a number of PFGE types, including PFGE types 14A (six strains from village 4), 14D (five strains from village 2), 16A (eight strains from villages 1,3 and 4 ), 16G (five strains from village 5), 21A (13 strains from villages 1 and 2) and 21B (10 strains from village 1). It was rare to find the same strains in different villages (Fig. 1). The similarity of 
each of the within-village genetic diversities did not indicate any particular geographical focus of increased genetic variation, for example there was as much genetic diversity in strains from village 1 as there was in the entire collection. The occurrence of frequent genetic recombination, the possible existence of epidemic clones and the high degree of strain diversity in $S$. pilosicoli may all help to explain some of the variation in the clinical syndromes observed in cases of intestinal spirochaetosis in humans and animals.

\section{ACKNOWLEDGEMENTS}

D.J.T. was in receipt of an Australian Pig Research and Development Corporation Postgraduate Scholarship and A.S.J.M. received an Australian Postgraduate Award. The study was funded in part by grants from the Australian Research Council, the National Health and Medical Research Council and Murdoch University. Roslyn Atyeo and Julie Ardley provided technical assistance. We thank all those individuals in Papua New Guinea who took part in this study.

\section{REFERENCES}

Atyeo, R. F., Oxberry, S. L. \& Hampson, D. J. (1996). Pulsed-field gel electrophoresis for sub-specific differentiation of Serpulina pilosicoli (formerly 'Anguillina coli'). FEMS Microbiol Lett 141, 77-81.

Barrett, S. P. (1990). Intestinal spirochaetes in a Gulf Arab population. Epidemiol Infect 104, 261-266.

Barrett, S. P., Holton, J. J. M., Hookey, J. V., Costas, M., Ganner, M., Mundy, R. \& Wright, D. J. M. (1996). Heterogeneity of human intestinal spirochaetes demonstrated by one-dimensional polyacrylamide gel electrophoresis of proteins visualised by ${ }^{35} \mathrm{~S}-$ methionine labelling and Coomassie blue staining. $J \mathrm{Med}$ Microbiol 45, 6-9.

Burr, E. J. (1968). Division sorting with mixed character types. I. Standardisation of character values. Aust Comp J 1, 97-99.

Burr, E. J. (1970). Division sorting with mixed character types II. Fusion strategies. Aust Comp J 2, 98-103.

Cooper, C., Cotton, C. W. K., Hudson, M. J., Kirkham, N. \& Wilmott, F. E. W. (1986). Rectal spirochaetosis in homosexual men: characterisation of the organism and pathophysiology. Genitourin Med 62, 47-52.

Duhamel, G. E., Muniappa, N., Mathieson, M. R., Johnson, J. L., Toth, J., Elder, R. O. \& Doster, A. R. (1995). Certain canine weakly beta-hemolytic spirochetes are phenotypically and genotypically related to spirochetes associated with human and porcine intestinal spirochetosis. J Clin Microbiol 33, 2212-2215.

Dwars, R. M., Davelaar, F. G. \& Smit, H. F. (1992). Infection of broiler chicks (Gallus domesticus) with human intestinal spirochaetes. Avian Pathol 21, 559-568.

Fournié-Amazouz, E., Baranton, G., Carlier, J. P. \& 7 other authors (1995). A series of isolations of intestinal spirochaetes from the blood of human patients. J Hosp Infect 30, 160-161.

Fusté, M. C., Pineda, M. A., Palomar, J., Vinas, M. \& Lorén, J. G. (1996). Clonality of multidrug-resistant nontypable strains of Haemophilus influenzae. J Clin Microbiol 34, 2760-2765.

Go, M. F., Kapur, V., Graham, D. Y. \& Musser, J. M. (1996). Population genetic analysis of Helicobacter pylori by multilocus enzyme electrophoresis: extensive allelic diversity and recombinational population structure. J Bacteriol 178, 3934-3938.
Hendrik-Nielsen, R. S., Orholm, M., Pedersen, J. O., HovindHougen, K., Teglbjaerg, P. S. \& Thaysen, E. H. (1983). Colorectal spirochetosis: clinical significance of the infestation. Gastroenterology 85, 623-667.

Hovind-Hougen, K., Birch-Andersen, A., Henrik-Nielsen, R., Orholm, M., J. O. P., Teglbjaerg, P. S. \& Thaysen, E. H. (1982). Intestinal spirochaetosis: morphological characterisation and cultivation of the spirochaete Brachyspira aalborgi gen. nov. sp. nov. $J$ Clin Microbiol 16, 1127-1136.

Humphrey, S. B., Stanton, T. B. \& Jensen, N. S. (1995). Mitomycin $\mathrm{C}$ induction of bacteriophages from Serpulina hyodysenteriae and Serpulina innocens. FEMS Microbiol Lett 134, 97-101.

Humphrey, S. B., Stanton, T. B., Jensen, N. S. \& Zuerner, R. L. (1997). Purification and characterization of VSH-1, a generalized transducing bacteriophage of Serpulina hyodysenteriae. J Bacteriol 179, 323-329.

Jenkinson, S. R. \& Wingar, C. R. (1981). Selective medium for the isolation of Treponema hyodysenteriae. Vet Rec 109, 384-385.

Koopman, M. B. H., Käsbohrer, A., Beckmann, G., van der Zeijst, B. A. M. \& Kusters, J. G. (1993). Genetic similarity of intestinal spirochetes from humans and various animal species. $J$ Clin Microbiol 31, 711-716.

Kostman, J. R., Patel, M., Catalano, E., Camacho, J., Hoffpauir, J. \& DiNubile, M. J. (1995). Invasive colitis and hepatitis due to previously uncharacterized spirochetes in patients with advanced human immunodeficiency virus infection. Clin Infect Dis 21, 1159-1165.

Kunkle, R. A., Harris, D. L. \& Kinyon, J. M. (1986). Autoclaved liquid medium for propagation of Treponema hyodysenteriae. $J$ Clin Microbiol 24, 669-671.

Law, C. L. H., Grierson, J. M. \& Stevens, S. M. B. (1994). Rectal spirochaetosis in homosexual men: the association with sexual practices, HIV infection and enteric flora. Genitourin Med 70, 26-29.

Lee, J. I. \& Hampson, D. J. (1992). Intestinal spirochaetes colonising Aborigines from communities in the remote north of Western Australia. Epidemiol Infect 109, 133-141.

Lee, J. I. \& Hampson, D. J. (1994). Genetic characterisation of intestinal spirochaetes and their association with disease. $J$ Med Microbiol 40, 365-371.

Lee, J. I., Hampson, D. J., Lymbery, A. J. \& Harders, S. J. (1993a). The porcine intestinal spirochaetes: identification of new genetic groups. Vet Microbiol 34, 273-285.

Lee, J. I., McLaren, A. J., Lymbery, A. J. \& Hampson, D. J. (1993b). Human intestinal spirochetes are distinct from Serpulina hyodysenteriae. J Clin Microbiol 31, 16-21.

Lymbery, A. J., Hampson, D. J., Hopkins, R. M., Combs, B. \& Mhoma, J. R. L. (1990). Multilocus enzyme electrophoresis for identification and typing of Treponema hyodysenteriae and related spirochaetes. Vet Microbiol 22, 89-99.

McLaren, A. J., Trott, D. J., Swayne, D. E., Oxberry, S. L. \& Hampson, D. J. (1997). Genetic and phenotypic characterization of intestinal spirochetes colonizing chickens and allocation of known pathogenic isolates to three distinct genetic groups. $J$ Clin Microbiol 35, 412-417.

McMillan, A. \& Lee, F. D. (1981). Sigmoidoscopic and microscopic appearance of the rectal mucosa in homosexual men. Gut 22, 1035-1041.

Maynard Smith, J., Smith, N. H., O'Rourke, M. \& Spratt, B. G. (1993). How clonal are bacteria? Proc Natl Acad Sci USA 90 , $4384-4388$.

Muniappa, N., Duhamel, G. E., Mathiesen, M. R. \& Bargar, T. W. 
(1996). Light microscopic and ultrastructural changes in the ceca of chicks inoculated with human and canine Serpulina pilosicoli. Vet Pathol 33, 542-550.

Nei, M. (1977). F-statistics and analysis of gene diversity in subdivided populations. Ann Hum Genet 41, 225-233.

O'Rourke, M. \& Spratt, B. G. (1994). Further evidence for nonclonal population structure of Neisseria gonorrhoea: extensive genetic diversity within isolates of the same electrophoretic type. Microbiology 140, 1285-1290.

O'Rourke, M. \& Stevens, E. (1993). Genetic structure of Neisseria gonorrhoeae populations: a non-clonal pathogen. $J$ Gen Microbiol 139, 2603-2611.

Park, N. Y., Chung, C. Y., McLaren, A. J., Atyeo, A. J. \& Hampson, D. J. (1995). Polymerase chain reaction for identification of human and porcine spirochaetes recovered from cases of intestinal spirochaetosis. FEMS Microbiol Lett 125, 225-230.

Rayment, S. J., Barrett, S. P. \& Livesley, M. A. (1997). Sub-specific differentiation of intestinal spirochaete isolates by macrorestriction fragment profiling. Microbiology 143, 2923-2929.

Surawicz, C. M., Roberts, P. L., Rompalo, A., Quinn, T. C., Holmes, K. K. \& Stamm, W. E. (1987). Intestinal spirochetosis in homosexual men. Am J Med 82, 587-592.

Tompkins, D. S., Waugh, M. A. \& Cooke, E. M. (1981). Isolation of intestinal spirochaetes from homosexuals. J Clin Pathol 34, 1385-1387.

Tompkins, D. S., Foulkes, S. J., Godwin, P. G. R. \& West, A. P. (1986). Isolation and characterisation of intestinal spirochaetes. $J$ Clin Pathol 39, 535-541.

Trivett-Moore, N. L., Gilbert, G. L., Law, C. L. H., Trott, D. J. \& Hampson, D. J. (1998). Isolation of Serpulina pilosicoli from rectal biopsy specimens showing evidence of intestinal spirochetosis. J Clin Microbiol 36, 261-265.

Trott, D. J., McLaren, A. J. \& Hampson, D. J. (1995). Pathogenicity of human and porcine intestinal spirochaetes in day-old specific pathogen free chicks: an animal model of intestinal spirochetosis. Infect Immun 63, 3705-3710.

Trott, D. J., Stanton, T. B., Jensen, N. S., Duhamel, G. E., Johnson, J. L. \& Hampson, D. J. (1996a). Serpulina pilosicoli sp. nov.: the agent of porcine intestinal spirochetosis. Int J Syst Bacteriol 46, 206-215.

Trott, D. J., Huxtable, C. R. \& Hampson, D. J. (1996b). Infection of newly weaned pigs with human and porcine strains of Serpulina pilosicoli. Infect Immun 64, 4648-4654.

Trott, D. J., Atyeo, R. F., Lee, J. I., Swayne, D. A., Stoutenburg, J. W. \& Hampson, D. J. (1996c). Genetic relatedness amongst intestinal spirochaetes isolated from rats and birds. Lett Appl Microbiol 23, 431-436.

Trott, D. J., Stanton, T. A., Jensen, N. S. \& Hampson, D. J. (1996d). Phenotypic characteristics of Serpulina pilosicoli the agent of intestinal spirochaetosis. FEMS Microbiol Lett 142, 209-214.

Trott, D. J., Jensen, N. S., Saint Girons, I., Oxberry, S. L., Stanton, T. B., Lindquist, D. \& Hampson, D. J. (1997a). Identification and characterization of Serpulina pilosicoli isolates recovered from the blood of critically ill patients. J Clin Microbiol 35, 482-485.

Trott, D. J., Combs, B. G., Mikosza, A. S. J. \& 7 other authors (1997b). The prevalence of Serpulina pilosicoli in humans and domestic animals in the Eastern Highlands of Papua New Guinea. Epidemiol Infect 119, 369-379.

Trott, D. J., Oxberry, S. L. \& Hampson, D. J. (1997c). Evidence for Serpulina hyodysenteriae being recombinant, with an epidemic population structure. Microbiology 143, 3357-3365. 